\title{
A cobrança do ouro do rei nas Minas Gerais: o fim da capitação - 1741-1750*
}

\author{
Joaquim Romero Magalhães"
}

A capitação foi um processo de cobrança de direitos régios que sofreu dura contestação. Aprovada e executada a partir de 1735, poucos anos depois surgem tentativas de revogar o processo e de regressar à forma anterior de cobrança; tentativas que se vão sucedendo, tendo êxito em 1750, quando o novo rei D. José decide a revogação. Estudar o processo de contestação à capitação é o objeto deste artigo.

Palavras-chave: Ouro - Quinto - Capitação

The king's gold tax in Minas Gerais: the end of capitation - 1741-1750

The capitation or individual tax was a collection procedure equivalent to one fifth or the gold extraction in Minas Gerais. This 1735 royal imposition lasted till 1750 and caused strong opposition from the municipalities in that region. Many attempts were made to abrogate it until the new king D. José decided to revoke it. It is the aim of this article to survey the capitation challenge process.

Keywords: Gold - Fifth - Capitation

La perception sur l'or aux Minas Gerais: la fin de la capitation - 1741-1750 La capitation ou impôt personnel était une procédure de perception équivalente à un cinquième de la recette de l'or extrait aux Minas Gerais. Cette imposition royale, de 1735, s'est prolongée jusqu'à 1750 et a soulevé une vive opposition de la part des municipalités de la région. Diverses tentatives furent entreprises pour la

\footnotetext{
* Artigo recebido e aprovado para publicação em junho de 2009.

** Professor da Faculdade de Economia da Universidade de Coimbra. E-mail: jromero@fe.uc.pt.
} 
révoquer, qui ont débouché finalement sur son abrogation, en 1750, par le nouveau Roi D. José.

Mots-clés : Or - Cinquième - Capitation

A audição das Câmaras da Capitania das Minas Gerais para estabelecer a capitação decidida em 1733 e executada a partir de 1735 levantava dificuldades. Prudente, mandava o rei no Regimento que antes de ser adotada fossem ouvidas as Câmaras das vilas cabeças de comarca (Vila Rica, Vila Real de Nossa Senhora da Conceição de Sabará, São João d'El-Rei e Vila do Príncipe) "e os mais, que for costume chamar em tais ocasiões para que ouvindo o que representarem, e fazendo as conferências necessárias, se escolha meio, que pareça mais conveniente a meu real serviço". Não se tratava apenas de conseguir que a tributação fosse lançada com suavidade, o que sempre se pretendia. É que a imposição de novas contribuições deveria ser aprovada pelos povos - era doutrina aceite. E a alta burocracia régia exigia respeito pela legislação e pelas velhas práticas - mesmo se já há muito que se não reuniam Cortes (desde 1699). Assim, houve que ficcionar que não se tratava de um tributo novo mas de uma simples mudança de forma de cobrança. Os juristas e teólogos analisariam e justificariam esse pagamento.1 Alguns defenderiam o direito de Sua Majestade, considerando-o uma enfiteuse - e portanto um contrato de direito privado. Assim, e por pouco que a realeza estivesse interessada em implicar as Câmaras no novo procedimento fiscal, politicamente não podia dispensar uma audição e uma colaboração que se queria conduzisse à aprovação da medida já decidida; porque significava encontrar não apenas uma aprovação mas uma como que cumplicidade para facilitar a sua aplicação.

Tinha D. João V estudado cuidadosamente a proposta de Alexandre de Gusmão para instalar a capitação e maneio: com grande miudeza e escrúpulo, "tinha examinado esta materia em mais de um anno de continuas discuçoens; as quais ainda depois disto duraram outro anno, antes que $\mathrm{S}$. Mag. ${ }^{\mathrm{e}}$ assentasse no firme conceito, em que ficou, de que a Capitação era o meio mais desem-

\footnotetext{
${ }^{1}$ André João Antonil, Cultura e opulência do Brasil por suas drogas e minas, Ed. Andrée Mansuy, Lisboa, CNCDP, 2001, cap. IX, p. 263-277.
} 
baraçado, e menos imperfeito de todos os que podiam ocorrer". ${ }^{2}$ Assim parece ter sido. Mas também não parece que assim tenha sido entendido.

Fosse como fosse, a Junta de autoridades e representantes dos concelhos, reunida nas Minas Gerais em 24 de março de 1734, sob a presidência do Conde das Galveias (hostil ao procedimento proposto), recusou aceitar a capitação, pelo que o Regimento foi parcialmente reformulado. Mantiveram-se tributos indiretos e diretos que, na formulação apresentada em primeiro lugar, se procuravam extinguir: como o dízimo, que a Igreja não queria abolido. A eliminação de algumas imposições com que Alexandre de Gusmão ideara acabar ficava desde logo impossibilitada. Claro que os procuradores concelhios preferiram, como sempre, que se fixasse uma cota, que então propuseram de 100 arrobas anuais - determinação transitória aprovada - o que implicava que fossem as Câmaras a lançar a finta sobre o conjunto da população, o que significava ainda, e desde logo, que os populares seriam os que mais teriam que desembolsar. Era o que as vereações pretendiam. Naturalmente. E assim se fez. Mas as coisas não podiam ficar nessa indeterminação. À pessoa real não se permitia que se acreditasse que a obrigavam "a ceder e a de certo modo entrar em compozição com os vassallos". O que ainda daria a conhecer como os súditos "eludem as suas reais determinações". ${ }^{3}$ O monarca não podia mostrar-se fraco e ser vencido em matéria de tanto relevo.

Em nova reunião de Junta de procuradores das Câmaras (Ribeirão do Carmo, Vila Rica, Vila do Príncipe, Sabará, São João d'El-Rei, São José d'ElRei e Caeté) com o governador Gomes Freire de Andrada, em 1 de julho de 1735, os povos por fim aceitaram que por cada escravo negro se pagasse por ano 4 oitavas e $3 / 4$ e no mesmo prazo pelos forros e ofícios; as lojas grandes, 24 oitavas; as medíocres, 16 e as inferiores 8 oitavas; as vendas pagariam 16 oitavas. Foi medida aprovada pela maioria dos procuradores presentes. ${ }^{4}$ Martinho de Mendonça, o enviado especial para a imposição e depois governador interino, tinha uma opinião já feita: “Tem o sistema a vantagem de proceder por um método geral e fácil, e com tal harmonia, que umas partes facilitam a execução

\footnotetext{
${ }^{2}$ Jaime Cortesão, Obras várias de Alexandre de Gusmão, Rio de Janeiro, Ministério das Relações Exteriores - Instituto Rio Branco, 1950, p. 238.

${ }^{3}$ Ibidem, p. 111.

${ }^{4}$ Códice Costa Matoso, Belo Horizonte, Fundação João Pinheiro - Centro de Estudos Históricos e Culturais, 1999, vol. I, doc. 17, p. 300-311; doc. 31, p. 354 e 362.
} 
das outras e todas fecham as portas às fraudes". ${ }^{5}$ Tratava-se de um método de cobrança bem articulado. Seria mesmo o "mais conveniente aos interesses de Sua Majestade, ao sossego dos povos e à liberdade do comércio". 6

Não obstante, talvez a capitação tenha sido o mais odiado de quantos procedimentos foram tentados como formas de obter o tributo do quinto para o rei, com as Câmaras fazendo representações e procurando mostrar quão maléfico era aos povos. Aliás, ficara consignado que os povos seriam livres de requerer a alteração do método agora aprovado. E o método vai tornar-se odioso ao vulgo - mas não só. Por ter sido retirada participação às governanças concelhias? Decerto, também. Fosse como fosse, dizia o seu criador Alexandre de Gusmão, este teria sido o "menos imperfeito" de todos os procedimentos de cobrança dos quintos do ouro. E, logo de imediato, em 1737, o próprio Conde das Galveias, então já Vice-Rei, tem que reconhecer que da sua aplicação resultava um "copioso fruto".

Para executar o novo método, nomeiam-se em 28 de janeiro de 1736 os primeiros funcionários régios com funções a isso dirigidas: os Intendentes. E logo o rei determina o pessoal de que cada Intendente irá dispor para, sob as suas ordens, se tratar de tudo o que respeitava à cobrança da capitação. Esta criação dos Intendentes iria obrigar a um mais numeroso grupo de oficiais régios. Embora a sua regulamentação ficasse para mais tarde, logo no Regimento, em 1734, se previam esses novos funcionários. Seria o Intendente um magistrado letrado, "pessoa de respeito, capacidade e zelo", para presidir aos trabalhos de cobrança do quinto, sendo auxiliado por um fiscal, um escrivão, um ajudante, um tesoureiro, um meirinho e quatro soldados dos dragões. Os oficiais das intendências teriam que saber escrever e contar bem "para a expedição breve que se requer nestes oficios". Importante seria o "alimpa${ }^{5}$ Jaime Cortesão, Alexandre de Gusmão e o Tratado de Madrid, Lisboa, Livros Horizonte, 1984, II vol., p. 438, 447 e 453.

${ }^{6}$ Jaime Cortesão, Alexandre de Gusmão e o Tratado de Madrid, tomo II, p. 453.

${ }^{7}$ Excelente síntese sobre as formas de cobrança do quinto por Carla Anastasia, "Entre Cila e Caribde: as desventuras tributárias dos vassalos de Sua Majestade", in: Varia Historia, Belo Horizonte, UFMG, n. 21, Julho de 1999, p. 237-243; Laura de Mello e Souza, Desclassificados do Ouro. A pobreza mineira no século XVIII, 3. ed., São Paulo, Edições Graal, 1990, p. 131; Jaime Cortesão, Obras várias de Alexandre de Gusmão, p. 228; "Documentos", in: Revista do Arquivo Público Mineiro, Anno XVI, vol. II, p. 270; Joaquim Romero Magalhães, "As Câmaras Municipais, a Coroa e a cobrança dos quintos do ouro nas Minas Gerais (1711-1750)", a publicar.

${ }^{8}$ José João Teixeira Coelho, Instrução para o Governo da Capitania das Minas Gerais (1782), Ed. Caio César Boschi, Belo Horizonte, Secretaria de Estado da Cultura - Arquivo Público Mineiro - Instituto Histórico e Geográfico Brasileiro, 2007, p. 218; Códice Costa Matoso, vol. I, docs. 10, 17, 51 e 53, p. 254-255, 308-311, 441-442 e 499. 
dor e examinador do ouro", que tinha de assistir à mesa do tesoureiro. Esses lugares foram postos a concurso público. ${ }^{9}$ A Intendentes concorriam bacharéis habilitados pela Mesa do Desembargo do Paço para servir os lugares de letras. A partir de 1744, era essa a regra, pois que o rei entendia que na Mesa do Desembargo do Paço havia mais experiência do préstimo e procedimento dos bacharéis e assim mais facilmente seriam escolhidos os que convinham aos lugares. ${ }^{10}$

Os Intendentes vão ser letrados e até, a partir de 1748, entram a substituir os Ouvidores-gerais nas faltas ou impedimentos destes - não havendo juiz de fora ${ }^{11}$ Serão as intendências mais uma parte dos mecanismos de presença da Coroa e de domínio desta sobre a Capitania. Instalam-se organismos de atuação fiscal de acrescida eficácia. No topo desta administração da fazenda situava-se a provedoria, comum a toda a Capitania e com exercício especializado de funções.

No próprio diploma da criação das intendências, de 28 de janeiro de 1736 se faz a ligação entre o processo da capitação e estes novos organismos, que se instalavam nas Minas Gerais (Vila Rica, Ribeirão do Carmo, Rio das Mortes, Sabará e Serro do Frio), mas também nas minas de São Paulo (Goyazes, Cuyabá, Parnaguá e Paranapanema) e ainda nas da Bahia (Minas Novas de Araçauí e Fanados).

O Regimento porque deverão interinamente regularse os executores do dito sistema, e por onde constará tambem a jurisdição, que devem ter os Intendentes, será o que provizionalmente communicar da minha parte aos Governadores, e Intendentes o Governador das Minas Geraes, com todas os aditamentos, ou explicações, que alem disso lhe participar, em virtude do que a experiência houver ensinado nas mesmas Minas Geraes, das quaes por serem as mayores, e mais povoadas do Brazil, he justo que se tire o exemplo, e norma para a execução do ditto sistema nas outras.

Em especial, fazia-se necessário cuidar da operação de matrícula dos escravos e de quantos estavam obrigados ao pagamento do censo e maneio, base do lançamento do tributo. ${ }^{12}$

\footnotetext{
${ }_{9}^{9}$ Arquivo Histórico Ultramarino (AHU), Con. Ultra., Brasil/MG, Cx. 32, Doc. 6; Doc. 21; Graça Salgado, Fiscais e Meirinhos: a administração no Brasil Colonial, 2. ed., Rio de Janeiro, Nova Fronteira, 1990, p. 89-92 e 293-297.

${ }^{10}$ AHU, Con. Ultra., Brasil/MG, Cx. 44, Doc. 27; doc. 51.

${ }^{11}$ AHU, Con. Ultra., Brasil/MG, Cx. 52, Doc. 97.

${ }^{12}$ AHU, Con. Ultra., Brasil/MG, Cx. 31, Doc. 71.
} 
A capitação e o censo escoravam-se em princípios de igualdade tributária e de proporcionalidade que nenhuma outra forma de cobrança pôde assegurar. Pretendia-se que fosse um processo "mais justo e livre de desigualdades". Talvez isso não interessasse aos pagadores mais abonados. A capitação tem sido dita "a maior vexação do povo destas Minas". Mas os queixosos são suspeitos. É gente da governança que sempre reclamaria porque esta teria sido a mais injusta das formas de cobrança - ou seria a que menos desvios autorizava? enquanto a afastava da cobrança, o que mais protestos motivaria ainda. Boas razões para não ser bem-vinda. Fosse como fosse, vigorou de 1735 a $1750 ; ;^{13}$ e vigorou porque era uma forma de cobrança que implicava uma sociedade estável e já controlada. A mobilidade dos arraiais precários nem sequer poderia permitir um arrolamento da população para se lançar e cobrar a capitação pelos escravos e o maneio pelas atividades produtivas de outra natureza que não a mineração. ${ }^{14}$

O fim do procedimento de cobrança da capitação que substituíra o imposto do quinto dos metais preciosos devidos a Sua Majestade pelas Ordenaçôes do Reino (tit. $34^{\circ}$ do Liv. II) ocorreu com o Alvará régio de 3 de dezembro de 1750. Mas não foi essa inovação decidida sem fundamento por D. José, sendo Secretário de Estado da Marinha e Negócios Ultramarinos Diogo de Mendonça Corte Real (filho). Diogo de Mendonça (pai) talvez não tivesse acatado de bom grado a introdução da capitação em 1734-1735. Disse-a "a mais injusta desigualdade que jamais se praticou" 15 e logo, em 1736, questionara Gomes Freire de Andrade, governador da Minas Gerais, sobre o assunto. Tinha opinião feita sobre a matéria: "sempre clamarey que deixem gozar os Povos do bem com que se achão, que o tempo nos mostrará se temos que emendar, e que havendo-o fie a S. Mag. ${ }^{\text {e }}$ de nós havermos de cumprir com o conceito que lhe temos merecido". ${ }^{16}$ Mantinha a sua mesma posição de antes do lançamento: "não cabe na clemencia e justiça de Sua Majestade impor um tributo tão

${ }^{13}$ Virgílio Noya Pinto, O ouro brasileiro e o comércio anglo-português (Uma contribuição aos estudos da economia atlântica no século XVIII), São Paulo, Companhia Editora Nacional - Brasiliana, 1979, p. 62-64. Bom resumo: Robert Allan White, "Fiscal Policy and Royal Sovereignty in Minas Gerais: the Capitation Tax of 1735", in: The Americas, Berkeley, Academy of American Franciscan History, vol. 34, n. 2, Oct. 1977, p. 207-229.

${ }^{14}$ Joaquim Romero Magalhães, "As Câmaras Municipais, a Coroa e a cobrança dos quintos do ouro nas Minas Gerais (1711-1750)", a publicar.

${ }^{15}$ Jaime Cortesão, Alexandre de Gusmão e o Tratado de Madrid, tomo II, p. 434.

16 "Documentos", in: Revista do Archivo Publico Mineiro, Belo Horizonte, Imprensa Oficial de Minas Geraes, 1911, Anno XVI, p. 243. 
onerozo, e dezigual, para resarcir os prejuizos, que cauzam os descaminhos dos quintos". Fosse ou não por desamor a Alexandre de Gusmão. ${ }^{17}$ Sempre o procedimento da capitação foi considerado gravoso, em especial porque substituía um imposto sobre o produto da mineração por um tributo pessoal. Muitos o pagavam, que nada tinham a ver com o metal ou com os trabalhos nas terras minerais. Nem essa era a lógica interna do dispositivo fiscal, o modo de se justificar ou de se executar. Tratava-se de um imposto geral sobre os rendimentos, específico para as populações da Capitania das Minas Gerais, que substituía o tributo devido ao rei do quinto do ouro minerado e que se aproximava de um imposto de renda. Apesar de tudo ter passado razoavelmente bem nas vilas das Minas durante estes dezesseis / dezessete anos em que vigorou a capitação (1735-1750), nunca fora o processo sentido como bom; menos ainda considerado justo. E assim tem sido apreciado pela história, com poucas exceções. ${ }^{18}$

Será de pensar que as primeiras manifestações de que o procedimento devia ser mudado ocorreram em 1741, a partir de Vila Rica. ${ }^{19}$ Invocava a Câmara da principal povoação da Capitania que "na criação das intendências ficou salvo ao povo e Câmara o direito de propalar o seu vexame a todo o tempo que se sentissem agravados", sem que se saiba o porquê de então se ter iniciado esse ataque ao procedimento da capitação. As queixas tinham dois motivos principais: o primeiro "consiste em que determinando-se que cada seis meses se pague certa quantia por capitação [sob] pena de não pagar mais um quarto de outava de ouro, se não espere o fim deles para executarse as penas"; o segundo "funda-se na experiência contínua de confiscação de escravos já manifestados todas as vezes que os seus senhores não pagão a capitação deles no fim de seis meses”. O mais grave, e que vai ser insistentemente invocado, é que a opressão fiscal acompanhava e causava a diminuição na extração do ouro. Era uma situação dita de miséria, forçada pela "falta de descobrimentos e extinção do ouro dos [descobertos] que há antigos”. Isso bastaria para despertar as atenções de Lisboa - quando não para alarmar a Corte -, porque as receitas com o ouro eram as principais do real erário em

\footnotetext{
${ }^{17}$ Jaime Cortesão, Alexandre de Gusmão e o Tratado de Madrid, tomo II, p. 460-468.

${ }^{18}$ Por todos, Roberto C. Simonsen, História Económica do Brasil 1500-1820, São Paulo, Rio de Janeiro - Recife, Companhia Editora Nacional, 1937, tomo II, p. 64-65. Em contrário, Jaime Cortesão, Alexandre de Gusmão e o Tratado de Madrid, tomo II, p. 474-475.

19 "Impostos na Capitania Mineira. Clamores e supplicas das Camaras em nome do Povo", in: Revista do Archivo Publico Mineiro, Ouro Preto, Imprensa Oficial das Minas Geraes, Anno II, 1897, p. 287-288.
} 
proveniência do Brasil. No ano seguinte, a Câmara de Vila Nova da Rainha (Caeté), para pedir a abolição, invocou a "impossibilidade dos moradores, a dificuldade e atrasamento da cobrança, e os continuos clamores, e lagrimas dos pobres". ${ }^{20}$ Seria assim, quando as entradas de ouro em Lisboa, na Casa da Moeda, e os resultados da capitação mostravam precisamente o contrário? A amoedação de ouro da década de 40 foi a mais elevada até então. No mesmo sentido, vão os dados recolhidos quanto ao quantitativo global da mineração. ${ }^{21}$ Mas seria esta uma quebra (ou melhor o receio de uma quebra) respeitante apenas à Capitania das Minas? Não é impossível se, como o próprio Alexandre de Gusmão parece aceitar, que a um declínio das lavras antigas - das Minas Gerais - se tivesse substituído um acréscimo notório dos novos descobertos: dos de Paracatu, ${ }^{22}$ mas ainda dos das Minas Novas de Araçauí e Fanado (no sertão da Capitania da Bahia), de Goiás e mesmo de Cuiabá e Mato Grosso.

Em 1743, o Cardeal da Mota pede a Gomes Freire de Andrada - que acumulava os governos do Sul do Brasil, incluindo o da Capitania das Minas Gerais - que lhe envie um parecer sobre o assunto, o que o general não deixa de executar, defendendo o status quo, que continua a parecer-lhe o melhor dos procedimentos. Ainda em 1743 Gomes Freire de Andrada redige uma longa exposição na defesa do procedimento da capitação, dirigida ao prelado que agia como se fosse ministro de D. João V. Defensor da capitação e maneio, só lhe ocorria como alternativa restaurar a Casa da Fundição e da Moeda (conforme tinham funcionado de 1725 a 1735) até a entrada em vigor da capitação e a tributação sobre os gêneros que na região se produziam. Teria o prelado algumas dúvidas sobre o tributo em vigor? Ou qualquer outro responsável em Lisboa? Pelo menos sentiriam necessidade de se informar quanto à execução do Regimento. E, não é improvável, que já então se tratasse de preparar uma nova forma de cobrança, embora tivessem passado apenas dez anos de aplicação. ${ }^{23}$

Queriam as Câmaras de Minas que as coisas mudassem? É evidente que sim. Não era comum uma contestação que em simultâneo provinha dos

\footnotetext{
${ }^{20}$ Ibidem, p. 288-289.

${ }^{21}$ Rita Martins de Sousa, Moeda e metais preciosos no Portugal Setecentista. 1688-1797, Lisboa, Imprensa Nacional / Casa da Moeda, 2006, p. 95-99; Roberto C. Simonsen, História Económica do Brasil 1500-1820, tomo II, p. 95 (média annual de 1741 a 1760 de 1,6 toneladas); C. R. Boxer, The Golden Age of Brazil. Growing Pains of a Colonial Society 1695-1750, reimp., Manchester, Carcanet Press, 1995, p. 333-338.

${ }^{22}$ Jaime Cortesão, Obras várias de Alexandre de Gusmão, p. 244.

${ }^{23}$ AHU, Con. Ultra., Brasil/MG, Cx. 43, doc. 85.
} 
representantes de todos os povos de uma Capitania ou região, como desta vez ocorreu: tomava a iniciativa de requerer a mudança do tributo à Câmara do Caeté, que escreveu às outras Câmaras de Minas para que também se queixassem ao rei. E assim fizeram, em 1744, Ribeirão do Carmo, São José d'El-Rei, São João d'El-Rei e Nossa Senhora da Conceição de Sabará. ${ }^{24}$ Foram queixas pungentes, dramatizadas quanto possível para comover os leitores lisboetas, o que teria resultado, porque, quase de imediato, a partir do ano seguinte, se abriu um alargado processo de consultas. Podia antever-se, pois, a mudança para breve, a partir daquele ano de $1745,{ }^{25}$ embora não fosse ainda de todo claro qual o procedimento a adotar, e parecesse aceito em Lisboa que o processo da capitação não era o melhor e que se devia encontrar um outro que o substituísse.

Começaram a juntarem-se pareceres negativos, corroborando os clamores e súplicas dos povos. Auscultavam-se oficiais régios das comarcas das Minas. Havia, segundo António Rodrigues de Macedo, Intendente de Vila Rica, que "remediar a mizeria que experimentavão os povos com a forma da capitação [...] e se cobre como dantes", o que implicava repor em funcionamento as Casas de Fundição e Moeda, embora "no comum se está vendo ser mais suave" este procedimento da capitação. Porém, a crise era grande. Essa era a queixa amplificada. Aliás, qualquer dos métodos pareceram "suaves a princípio, e intoleráveis depois". ${ }^{26}$ Achava-se aquele procedimento das Casas de Fundição e Moeda "ajustado com as leys do Reino, e o mais conforme à igualdade porque paga cada hum somente do que extrahe, ou tem”. E o grande obstáculo à satisfação residia em que o "tributo compreende tanto aos que tirão ouro; como aos que o não tirão". ${ }^{27}$ A compreensão de uma nova imposição sobre o rendimento não passara para a população, e por isso sempre o protesto se basearia nesta evidência: tanto pagava o mineiro como o roceiro; tanto pagava o escravo doméstico como o que garimpava; tanto o moço do cego como a preta da cozinha. Essa era a desigualdade de situações sempre sentida - porque o tributo para todos era o mesmo. Importava a cabeça, não o ofício ou ocupação.

\footnotetext{
24 "Impostos na Capitania Mineira. Clamores e supplicas das Camaras em nome do Povo", in: Revista do Archivo Publico Mineiro, Ouro Preto, Imprensa do Estado, 1897, Anno II, p. 288-309.

${ }^{25}$ AHU, Con. Ultra., Brasil/MG, Cx. 44, Doc. 85; Cx. 45, Doc. 99.

${ }^{26}$ AHU, Con. Ultra., Brasil/MG, Cx. 45, Docs. 75 (Vila Rica), 76 (Serro do Frio), 77 (Mariana), 86 (Sabará) e 97 (Rio das Mortes).
}

${ }^{27}$ AHU, Con. Ultra., Brasil/MG, Cx. 47, doc. 59. 
Contudo, o governador Gomes Freire de Andrada continuava a não ter dúvidas sobre o procedimento da capitação; seria o seu defensor, para evitar que se regressasse ao "antigo labirinto", atacando os que o queriam abolido: "suspiram hoje estes povos por fraudarem o quinto, exercicio que sempre tiveram, e porque trabalharão em outros tempos com insolente forsa, e depois com pernecioza indústria". E tem consciência de que de "se seguirem as propostas que neste papel se reprezentão, se experimentará grande contentamento nos póvos, e igual dementação na cobrança do quinto, que não he ainda o que pretende a fazenda Real [...]". Admitia alguns alívios, mas que o procedimento se mantivesse. ${ }^{28}$

Nos demais pareceres produzidos pelos Intendentes com experiência da cobrança leem-se apreciações muito favoráveis à capitação, mas poucos são os que defendiam que se mantivesse:

A actual sistema da capitação; tem as conveniências [...]; de não permittir descaminhos delle; de evitar cazas de moeda, e barra falsa; em consequência, devassas, prizoens, e todas as mais vexações, que dahi vem aos Povos; a quem nesta parte deixa viver em socego, e quietação; e ultimamente; ainda as suas penas, não arruinão de golpe, como as outras.

Evitar os descaminhos e em simultâneo evitar a repressão que era especialmente gravosa, mas se considerava indispensável. Mas, lê-se nos requerimentos e pareceres, introduziram-se desigualdades que inabilitaram para novos descobrimentos e outras perdas que levaram a Capitania à sua “inegavel decadencia”. ${ }^{29}$ Logo, havia que mudar. Porém, e a acreditar em Alexandre de Gusmão, D. João V não se deixou impressionar pelos clamores que até ele se elevavam, "enquanto se conservou no seu natural vigor". O monarca entrara na fase terminal do reinado com uma saúde depauperada, e com os organismos do Estado a sofrerem com falta de orientação e em descoordenação entre eles. ${ }^{30}$

Este processo de consultas abriu o caminho a que se discutisse a capitação. Há que suspeitar que em 1748 já estaria decidida essa revogação, embora ainda não estivesse escolhido o procedimento que o substituiria: o que revela a enorme dificuldade encontrada pelos adversários da capitação;

\footnotetext{
${ }^{28}$ AHU, Con. Ultra., Brasil/MG, Cx. 45, doc. 97; Cx. 52, doc. 80.

${ }^{29}$ AHU, Con. Ultra., Brasil/MG, Cx. 54, Doc. 7.

${ }^{30}$ Jorge Borges de Macedo, s. v. "D. João V”, in: Joel Serrão (direc.), Dicionário de História de Portugal, Lisboa, Iniciativas Editoriais, 1964-1971.
} 
ou tão só aconteceu, como em tantas outras matérias de Estado, que ficou em suspenso nos anos terminais de D. João V. Mas a decisão de a revogar estaria tomada. A reforçar essa decisão veio o parecer elaborado pelo desembargador Tomé Gomes Moreira, datado de Lisboa, de 1749. Embora a capitação tenha sido suposto o método mais conveniente,

foi esse arbítrio, pela formalidade com que os executores o estabeleceram, tão notoriamente prejudicial que toda a sua execução é contra os preceitos da consciência e contra os ditames da razão, ofendendo-se as leis divinas, quebrando-se as humanas, faltando-se à equidade e rectidão da justiça, executando-se violências, oprimindo-se os povos e causando-se ao mesmo serviço real danos irreparáveis. ${ }^{31}$

Não se podia dizer pior. E partia o desembargador para demonstrar que só deviam pagar os que mineravam, porque senão estava-se perante um tributo pessoal injusto e desigual, pelo que vai insistir na cobrança apenas aos que mineram e não nos outros, porque

o sistema da capitação é contrário a todos os Regimentos, imposições e tributos do Reino, não necessita de mais prova que os mesmos Regimentos, e tudo se achará regulado conforme o rendimento das fazendas que cada um tem ou conforme a agência e o ofício que exercita. E esta desigualdade e rectidão se não acha no sistema da capitação, pelo qual tanto há de pagar o mineiro pobre como o rico, e na mesma forma tanto hão de pagar os que têm escravos que não mineram como todos que se ocupam no exercício de extraírem ouro, e esta desigualdade é notoriamente injusta e muito prejudicial à conservação das Minas. ${ }^{32}$

Argumentos que não cansariam os adversários da cobrança, que finalmente teriam ganho de causa.

Em 6 de outubro de 1749, reuniu uma Junta ad hoc para responder ao pedido de Sua Majestade sobre a capitação. Seria já um passo do final do processo de revogação. E, mesmo perante o parecer favorável de Gomes Freire de Andrada, a maioria dos conselheiros foi de opinião contrária ao procedimento em vigor: "o que prezentemente se pratica de se cobrar por capitação he o mais violento, e o que menos se conforma com as regras de direito, e com as da equidade, e justiça [...]". Entendiam que devia ser contratada e arrendada a cobrança, como ocorria com outras rendas. Tinha sido essa, já em 1733, a

${ }^{31}$ Códice Costa Matoso, vol. I, doc. 53, p. 466.

${ }^{32}$ Ibidem, p. 471. 
proposta do então Secretário de Estado Diogo de Mendonça Corte-Real (pai), ${ }^{33}$ que então tornava a emergir. Na sua impossibilidade, passariam à criação de Casas de Fundição, como antigamente houvera.

Contra qualquer dessas soluções, peremptoriamente e como seria de esperar, estava Alexandre de Gusmão. Para o autor do método ainda em vigor, "qualquer dos meyos que se escolhão abolindo a capitação, alem de diminuir de hum jacto a quinta parte dos cabedaes das Minas se hão-de seguir taes inconveniente, que brevemente se mostrarão a necessidade de a tornar a estabelecer". Temia novos distúrbios, como os que marcaram antigos procedimentos; e, se cessasse a capitação, defendia que o melhor seria arrendar o quinto por distritos. Entendia, ainda, que deviam ser convocados os povos das Minas para que os procuradores das Câmaras em Junta "com toda a liberdade digão se querem a capitação moderada, ou o quinto arrendado" e que se pusesse em prática o método que fosse escolhido. Teria sido o único participante - em nove - a votar contra a proposta de abolir a capitação, ${ }^{34}$ que aconteceu, por fim, em 3 de dezembro de 1750, lei que não foi já aprovada por D. João V, mas pelo filho e herdeiro D. José I.

Uma Junta se reuniu nas Minas, sob a presidência de Gomes Freire de Andrada, em 18 de novembro de 1751. Tratava-se de bem administrar a transição de um processo de cobrança para outro, sem deixar em dívida os pagamentos atrasados. ${ }^{35}$ Não se julgava a capitação um método perfeito nem livre de desigualdades, reconhecia Alexandre de Gusmão, pois bem sabia "que não he esperavel a perfeição em Lei alguma humana, e muito menos nas de cobrança de direitos publicos". Tê-la-ia apontado como o processo que "levava na forma da cobrança pela mesma medida o pobre e o poderoso". ${ }^{36}$

Revogado e substituído o procedimento, Alexandre de Gusmão não hesitou em escrever logo a 19 de dezembro de 1750: nas Minas ficariam satisfeitíssimos "os Ecclesiasticos, os homens da Governança, os poderosos, os mercadores, os comboieiros" porque se lhes abriam os "caminhos para se isentarem do pagamento delle [quinto]". É que a lei tinha sido fabricada por quem das Minas tinha mais zelo do que experiência. ${ }^{37}$ Logo se levantaram

\footnotetext{
${ }^{33}$ Jaime Cortesão, Alexandre de Gusmão e o Tratado de Madrid, tomo II, p. 417 e 434.

${ }^{34}$ AHU, Con. Ultra., Brasil/MG, Cx. 54, Doc. 18.

${ }^{35}$ Códice Costa Matoso, vol. I, doc. 77, p. 613-617.

${ }^{36}$ Jaime Cortesão, Obras várias de Alexandre de Gusmão, Parte II, tomo I, p. 250; Jaime Cortesão, Alexandre de Gusmão e o Tratado de Madrid, tom. II, p. 475.

${ }^{37}$ Jaime Cortesão, Obras várias de Alexandre de Gusmão, Parte II, tomo I, p. 229.
} 
protestos contra a lei novíssima, que reinstalava as Casas de Fundição... ${ }^{38}$ Embora se retomasse a proposta aprovada na Junta de 24 de março de 1734, tal como fora apresentada ao Conde das Galveias, e agora tida em Lisboa como a preferida pelos Procuradores dos Povos das Minas, assim também a considerou Sebastião José de Carvalho e Melo, em parecer do ano em que foi revogada a capitação - revogação em que parece nada ter intervindo. ${ }^{39}$ Mas contra esse quantitativo logo protestaram os povos, que arguiam estar a terra incapaz de os perfazer... ${ }^{40}$

Também se renovava a importância das Câmaras no processo de cobrança dos quintos, sem regresso à total responsabilidade, porque, embora aligeiradas no pessoal de serviço, se mantinham as Intendências, o que era contraditório com o argumento de que se tratava de uma despesa que se poderia poupar. O que também se não vai colher, porque a lei não permitirá que as Câmaras, por si só, administrem a distribuição dos quantitativos a pagar e a derrama. Junto delas, tinham de participar nos lançamentos o Ouvidor, o Intendente, e o Fiscal de cada Comarca. ${ }^{41} \mathrm{O}$ fiscal deixava de ser um homem de letras nomeado pelo rei: em sua vez, passava a ocupar o lugar "hum homem bom dos principaes da terra, nomeado cada tres mezes pelas respectivas Câmaras por pluralidade de votos, e approvado pelos Ouvidores (Cap. III, ns $1 \mathrm{e}$ 2)". As intendências seriam depois soldadas às renascidas Casas de Fundição (Regimento de 4 de março de 1751); ${ }^{42}$ e assim continuaram os Intendentes a desempenhar um papel central na recepção do quinto.

Mesmo assim, o procedimento não podia ter deixado de reforçar o poder das vereações, porque se renovava a importância das Câmaras na cobrança dos quintos - sobretudo em caso de derrama, como veio a acontecer uns anos mais tarde. Ficaram com a responsabilidade de garantir a entrega à Real Fazenda das cem arrobas anuais de ouro e de encontrar meio de as perfazer, quando a cobrança as não atingia, do que Alexandre de Gusmão se apercebe, e avisa. Porque a derrama leva a que sejam sem número "as injustiças, e desigualdades, e por isso se reprovou sempre este meio". ${ }^{43}$ As avenças teriam ainda que ser

\footnotetext{
${ }^{38}$ Códice Costa Matoso, vol. I, docs. 55 a 60, p. 509-529.

${ }^{39}$ AHU, Con. Ultra., Brasil/MG, Cx. 57, Docs. 21 e 22.

${ }^{40}$ AHU, Con. Ultra., Brasil/MG, Cx. 28, Doc. 74.

${ }^{41}$ Antonio Delgado da Silva, Colleç̧ão da Legislação Portugue:a. 1750- 1762, Cap. I, n. 3, p. 22.

${ }^{42}$ Regimento para as Intendências e Casas de Fundição, in: Antonio Delgado da Silva, Collecção da Legislação Portugueza. 1750-1762, Lisboa, Typografia Maigrense, 1830, p. 40-52.

${ }^{43}$ Jaime Cortesão, Obras várias de Alexandre de Gusmão, Parte II, tomo I, p. 233.
} 
consideradas como regulando contratos entre particulares, para não terem um caráter de novos tributos. ${ }^{44}$

Não deixaram porém as Câmaras de levantar queixas contra a lei novíssima que então se punha em vigor. Mesmo os que não queriam a capitação também iriam protestar contra o novo procedimento fiscal, que desde logo implicava elaborar Regimentos para as Casas de Fundição, de que foi encarregado Diogo de Mendonça Corte Real, o competente Secretário de Estado. Rapidamente o Regimento foi elaborado e presente ao Conselho Ultramarino, que sobre ele deu parecer a 22 de fevereiro de 1751, sendo sem tardar aprovado pelo Rei, em 4 de março, não sem que Sua Majestade, vistas algumas das objeções levantadas, deixasse por advertir os conselheiros: tinham a inviolável obrigação de respeitar as leis régias e de cumprir com pontual observância o que lhes era mandado. Abreviavam-se as decisões para permitir o envio a tempo do Regimento para as Minas Gerais, isto porque o Conselho Ultramarino, para além de dar a sua opinião sobre o Regimento, entendeu criticar a própria lei. E isso, no despotismo régio agora em instalação, já se tornava insuportável. A crítica, que era respeitosa e parecia bem intencionada, mostrava algumas deficiências do dispositivo legal aprovado, em que poderia haver prejuízo para os mineiros, para a Fazenda Real, para o comércio e fazer perigar o sossego público. Mas era uma crítica que não punha em causa o ordenamento escolhido; antes, procurava apontar como aperfeiçoá-lo. ${ }^{45}$

A recepção da novíssima lei de 3 de dezembro de 1750 não foi porém como se esperaria em Lisboa. Claro que os municípios agradeciam à "real grandeza de Sua Majestade o benefício que fez a estas Minas em desterrar delas o insuportável jugo da capitação”. Mas logo suplicavam que fosse comutado o meio da cobrança para a imposição das 100 arrobas anuais de ouro, porque entendiam que a proposta de 17 anos atrás já não era válida: então tinham-na feito por se encontrarem "coactos, de verem iminente o reconhecido vexame da capitação, e de tantos malles escolherão o que então lhe pareceo menor". A situação econômica era outra. Já não parecia que as riquezas que da terra se extraíam eram infinitas. A extração da riqueza tinha-se reduzido pela intensidade do que tinha sido minerado, pelo que então já não poderiam pagar tanto, preferindo ajustar-se ao que fosse quintado nas Casas de Fundição. ${ }^{46}$

As Câmaras da Capitania mais uma vez coordenavam as suas posições porque essa conformidade entre todas dava eficácia para a obtenção da grande

${ }^{44}$ Ibidem, p. 243 e 245.

${ }^{45}$ Códice Costa Matoso, vol. I, doc. 67, p. 581-591.

${ }^{46}$ AHU, Con. Ultra., Brasil/MG, Cx. 28, doc. 74. 
justiça que esperavam do rei. Assim o escreveu a vila de São José d'El-Rei. ${ }^{47}$ Vila Rica, como a mais importante das povoações, onde se concentravam mais delegações do poder régio, serviria como que de organizador das propostas alternativas - embora nunca se alvitre o regresso à invocada opressão que a capitação representava, precisamente ao contrário do que supunha e desejava Alexandre de Gusmão. ${ }^{48}$ Ao criador não agradaria ver desaparecer ingloriamente a criatura que tanto trabalho dera a instalar e cujos bons resultados eram tidos agora como um vexame pelos povos.

De redação de um profissional do foro, que não de um qualquer oficial local, a representação de Vila Rica contra os dispositivos da lei novíssima era clara. De se seguir o disposto na lei teriam "gravíssimo prejuízo e eminente ruína", porque descaminhos na declaração do ouro sempre haveria, que a terra, com seus desertos, sertões, veredas e infinitos caminhos ocultos, os facilitaria. ${ }^{49}$ E qualquer tributo teria como inevitável resultado "prantos, clamores, e ruínas populares e de nenhuma sorte proveito à real Fazenda". ${ }^{50}$

Sempre o procedimento de cobrança havia de ser tido por mal: qualquer que fosse.$^{51}$ Sabia-se com certeza que seria odioso às populações: ao vulgo diria Martinho de Mendonça do alto da sua empáfia iluminista - esse era o efeito da cobrança do quinto devido a Sua Majestade sobre os povos da Capitania das Minas Gerais. ${ }^{52}$

${ }^{47}$ Códice Costa Matoso, vol. I, vol. I, doc. 57, p. 517

${ }^{48}$ AHU, Con. Ultra., Brasil/MG, Cx. 54, doc. 18.

${ }^{49}$ Cod. Costa Matoso, Parecer de Tomé Gomes Moreira, de 1749, p. 464 ss.

50 "Impostos na Capitania Mineira. Clamores e supplicas das Camaras em nome do Povo", in: Revista do Archivo Publico Mineiro, Anno II, p. 287.

${ }^{51}$ Jaime Cortesão, Alexandre de Gusmão e o Tratado de Madrid, tomo II, p. 476.

${ }^{52}$ Documentação consultada, cuja transcrição está feita, que contém as seguintes peças: 1 . Edital de Gomes Freire de Andrada contra fraudes na matrícula dos escravos (28 de abril de 1740); 2. Carta de Gomes Freire de Andrada ao Cardeal da Mota (14 de setembro de 1743); 3. Carta da Câmara de Vila Rica ao Rei (21 de outubro de 1744); 4. Representação dos oficiais da Câmara da Vila de Nossa Senhora do Bom Sucesso das Minas Novas de Araçauhi ao Rei (30 de dezembro de 1744); 5. Carta de Gomes Freire de Andrade ao Rei (20 de janeiro de 1745); 6. Parecer do Intendente de Vila Rica António Rodrigues de Macedo (26 de agosto de 1745); 7. Parecer do Intendente da Capitação e dos Diamantes do Serro do Frio Plácido de Almeida Montoso (2 de setembro de 1745); 8. Parecer do Intendente da Cidade de Mariana Domingos Pinheiro (2 de setembro de 1745); 9. Parecer do Intendente da Comarca do Sabará Mateus Franco Pereira (20 de setembro de 1745); 10. Parecer do Intendente da Comarca do Rio das Mortes Bento António dos Reis Pereira (30 de setembro de 1745); 11. Carta de Gomes Freire de Andrade a António Guedes Pereira (5 de outubro de 1745); 12. Carta da Vila Real do Sabará ao Rei (24 de setembro de 1746); 13. Carta de Gomes Freire de Andrada a Marco Antonio de Azevedo Coutinho (30 de agosto de 1748); 14. Assento de uma Junta sobre a capitação (6 de outubro de 1749); 15. Voto de Sebastião José de Carvalho e Melo sobre a cobrança dos quintos (20 de novembro de 1750). 